\section{Adopting physical activity to help combat end-stage renal disease}

\author{
Wilson Du
}

\section{Wilson Du}

Alameda, California, USA

Wilson $\mathrm{Du}$ is on Instagram at @ RenalWarrior2016.

\section{DIAGNOSIS AND BEHAVIOURAL SHIFT}

I was diagnosed in June 2016 with endstage renal disease (ESRD). At the time of diagnosis, I was 34 years old, morbidly obese, had serious hypertension, and I felt broken spiritually and physically. I spent the first few months following my diagnosis in a wheelchair, unable to walk, and bedridden for the most part.

Since then, I have conquered many fears, both physically and mentally, and have used my mindset to become a 'Renal Warrior'. I have trained my body and mind to be more athletic, and thanks to this mindset I have lost over 130 lbs (59 $\mathrm{kg}$ ) since I was diagnosed. Currently I am undertaking haemodialysis treatment in preparation for a living kidney donor.

\section{THE IMPACT OF DIAGNOSIS}

At the time of my diagnosis, I presumed that a simple surgical procedure or taking prescribed medications would fix my health and situation. I was terrified. Initially, this news made me think deeply about my life, if I was happy, and how I would leave this world if I passed. I wanted to do better, but I also wanted to ensure I pass on some goodness in the world, both for my immediate family and for the wider renal community.

\section{OVERCOMING INITIAL CHALLENGES}

My main concern initially was to find a way to lose weight as most of the time I relied on a wheelchair to move around. I was unable to participate in any physical activity and my options for weight loss felt limited. For me, my renal disease was only one part of wanting to get fit and well-I also had a strong desire to become empowered.

\section{IMPROVEMENTS SINCE ADOPTING PHYSICAL ACTIVITY}

As a kidney dialysis patient, my energy levels are one of the most important

Correspondence to Wilson Du, Renalwarrior2016, Alameda, California, United States; wilson.du@gmail.com 'resources' that will decline after each treatment session. Feeling constantly drained and tired is a serious side effect of the treatment. I would have to say that one of the biggest improvements is my drive to live and stay active. I have trained my body and mind to be more athletic, and this has become my philosophy.

\section{CURRENT FOCUS AS RENAL WARRIOR}

My mission is to prove to all renal patients, no matter where they are in the world, that they can still live a meaningful life while on haemodialysis. I want to support fellow patients to get to this point, and I want the wider world to understand and appreciate the physiology of these patients. As patients with ESRD, we do not know how long we have left in this life. I am constantly challenging myself every day to track my goals and results. I hope that as Renal Warrior I can serve as an active 'beacon' where renal patients become fit and ready for a kidney transplant. I do believe that since implementing physical activity in my life and adopting a daily routine, I have helped to boost my confidence and energy and empower myself. Ultimately participating in physical activity has and is extending my life.

\section{SUPPORT FOR MY RENAL PEERS}

Here in the USA the healthcare system is quite rigid; patients need to meet 'elements of criteria' before having a transplant. That was an important point for me to become motivated, but I was also motivated by my family, friends and all the renal patients who are in similar circumstances and facing the same journey.

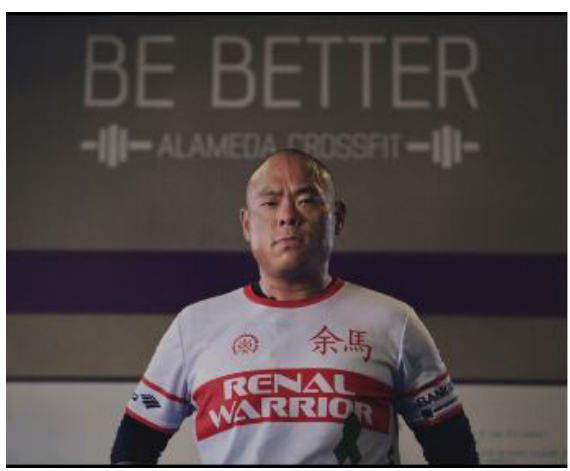

Figure 1 Wilson Du, Renalwarrior2016.
I am quite active on social media and have an Instagram page (@RenalWarrior2016 - figure 1). By posting activities relating to my renal health and physical activity, I can share my journey with followers. The Renal Patient Support Group (RPSG) UK is also doing great work to support the international renal community and helping to bridge gaps in renal education surrounding physical activity for renal patients. By sharing information, patients are helping each other, and this is all part of our shared journey.

\section{BENEFITS OF PHYSICAL ACTIVITY FOR RENAL PATIENT CARE}

Kidney patients undergo several forms of monitoring throughout their care plans. Whatever chronic kidney disease stage my fellow peers are in, keeping active has many advantages. I believe that it is vital to ensure that physical activity plays a role in our general care plan as patients with chronic kidney disease. However, I also believe that we need more understanding from other professionals, including nutritionists, laboratory scientists and physiotherapists, about what we should be doing to improve our lives.

New technologies and tracking devices have a place to help monitoring, but it would be great to have an understanding from healthcare scientists about how my laboratory parameters are affected by physical activity-both negatively and positively. It would also be helpful to pair the scientific aspect of this along with the application of physical activity to get a better understanding.

\section{RECOMMENDATIONS FOR PEERS WITH \\ CHRONIC KIDNEY DISEASE}

I would recommend start small, track what is done and constantly improve. We all have 'off' days and feel constantly challenged by elements of kidney disease. It is important to keep a positive mindset because only then will getting involved in physical activity have a decisive impact on the outcome of our health and our disease.

\section{EDUCATIONAL SUPPORT FOR CHRONIC KIDNEY DISEASE AND PHYSICAL ACTIVITY}

This is perhaps one of the single most important entities, where the RPSG team is making headway relating to providing patients baseline understanding of physical activity. I believe this has been a somewhat neglected focus for health professionals. It is important to have the appropriate support because at present there is not enough accurate information 


\section{Patient voices}

'out there' linking chronic kidney disease and physical activity.

Three pieces of advice for clinicians working with patients who have ESRD:

1. Communicate and understand your patients smarter.

It is important for health professionals to become more aware of health and physiology. Knowing the body and how the kidneys function, especially in relating to blood pressure and physical activity, is insight that kidney patients would benefit from.

2. Identify appropriate and tailoredcentred information for your patients. All patients go through challenges when diagnosed with chronic kidney disease. It is important that professionals provide specific information, using data and analytics, so patients can engage with their healthcare better.

3. Understand there is a human being behind the clinical scenario.

All patients go through various emotional states when living with chronic kidney disease. Clinicians working with patients should see them as 'partners in health' so that helps balance the compassion in clinical care.

Acknowledgements I would like to take this opportunity to thank Re-Phew! Consulting.

Funding The authors have not declared a specific grant for this research from any funding agency in the public, commercial or not-for-profit sectors.

Competing interests None declared.
Patient consent for publication Obtained.

Provenance and peer review Not commissioned: internally peer reviewed.

Author note This work was an invited piece for the $B J S M$ 's Patient Voices section highlighting patient case study surrounding chronic kidney disease (end-stage renal disease).

(c) Author(s) (or their employer(s)) 2020. No commercial re-use. See rights and permissions. Published by BMJ.

\section{Check for updates}

To cite Du W. Br J Sports Med 2020;54:495-496.

Accepted 20 June 2019

Published Online First 5 July 2019

Br J Sports Med 2020;54:495-496. doi:10.1136/bjsports-2019-100908

ORCID iD

Wilson Du http://orcid.org/0000-0002-6006-8360 